\title{
BMJ Open Australian community pharmacy services: a survey of what people with chronic conditions and their carers use versus what they consider important
}

\author{
Sara S McMillan, ${ }^{1,4}$ Fiona Kelly, ${ }^{1,2}$ Adem Sav, ${ }^{1,3}$ Michelle A King, ${ }^{4}$ \\ Jennifer A Whitty, ${ }^{1,5}$ Amanda J Wheeler ${ }^{1,2}$
}

To cite: McMillan SS, Kelly F, Sav A, et al. Australian community pharmacy services: a survey of what people with chronic conditions and their carers use versus what they consider important. BMJ Open 2014:4:e006587. doi:10.1136/bmjopen-2014006587

- Prepublication history for this paper is available online. To view these files please visit the journal online (http://dx.doi.org/10.1136/ bmjopen-2014-006587).

Received 11 September 2014 Revised 18 November 2014 Accepted 19 November 2014

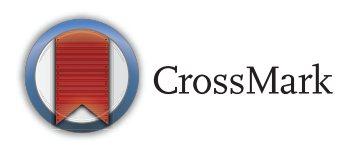

For numbered affiliations see end of article.

Correspondence to Sara S McMillan; s.mcmillan@griffith.edu.au

\section{ABSTRACT}

Objective: To explore the purpose/s for which people with chronic conditions and their carers use Australian community pharmacies, and compare this to what pharmacy services they consider important, from the perspectives of both consumers and pharmacists.

Design: An exploratory study involving a survey, which asked participants to indicate the pharmacy services they had ever used, and rate the importance of 22 pharmacy services to them, or the person they care for, or for their consumers if a pharmacist.

Setting: Four regions of Australia: Logan-Beaudesert and Mt Isa/North West region, Queensland, Northern Rivers, New South Wales, and the Greater Perth area, Western Australia.

Participants: Surveys were undertaken with 602 consumers and 91 community pharmacists.

Results: Community pharmacy is predominantly used to obtain advice about medication and whether a doctor's visit is necessary, as well as for monitoring and screening services. Pharmacy services that were patient centric were important, such as individualised medication advice and respectful care, as well as tools or procedures to facilitate streamlined medication access. Less important services included adult vaccinations and health and wellness programmes. Carers identified services that assisted them with their specific role/s to be important.

Overall, community pharmacists had a good understanding of the services that were important to people with chronic conditions and their carers.

Conclusions: People with chronic conditions and their carers not only care about what services are delivered, but how they are delivered; they sought services that generally improved their access to medication and information, but in a way that was patient centred. Ultimately, pharmacists understood the importance of patient-centred care for people with chronic conditions and their carers, perhaps indicating a greater acceptance of integrating patient-centred care into their everyday practice.

\section{INTRODUCTION}

The scope of practice for pharmacists is expanding, yet not all new roles or pharmacy
Strengths and limitations of this study

- This large, consumer-driven study has provided in-depth information in an area that has received limited attention, that is, what pharmacy service or care is important to people with chronic conditions and their carers.

- This study was informed by, and adds to, previous findings from a larger project.

- Most studies have generally explored pharmacists' perceptions or preferences for extended or future roles, or patient-centred services. Instead, pharmacists were asked to reflect on what they thought their clients' priorities would be.

- A longitudinal approach would give an indication if a person's use of pharmacy changes over time, particularly if the condition worsens.

- Researchers could not ascertain if the services participants did not access were actually available in the pharmacy they used.

services beyond medication advice or supply have been utilised to their full potential. For example, Portuguese consumers did not identify the need for, or the pharmacist's role in, therapeutic drug monitoring. ${ }^{1}$ This may be for many reasons, including lack of consumer awareness of these services, or the pharmacist's role. ${ }^{2-4}$ A recent Australian project explored the needs of consumers with respect to community pharmacy, and highlighted the importance of increasing public awareness of pharmacy services. ${ }^{5}$ Unfortunately, this is no different from a recommendation made by a similar project 10 years earlier. ${ }^{6}$

While there are reports of pharmacist awareness weeks or campaigns, ${ }^{7-9}$ an evaluation of their impact is limited, with research mostly assessing the effectiveness of specific health campaigns or programmes, which involve pharmacists. ${ }^{10-13}$ Furthermore, it has been proposed that 
simple awareness of available services is not enough to facilitate change in pharmacy utilisation. ${ }^{4}$ Further factors may need to be considered, such as increasing consumer trust in the pharmacist's ability to perform new services or different roles. ${ }^{4}$ Schommer and Gaither $^{3}$ identified the importance of breaking the 'care and respect' cycle $;^{3}$ if pharmacists show little care for the consumer, then the result is a corresponding level of respect for pharmacists' skills, with the cycle continuing. It has been proposed that pharmacy services need to be designed in a way to improve public trust, such as continual consultations with one pharmacist. ${ }^{4}$ Given that a recent concept analysis of treatment burden identified that poor-health professional-consumer relationships and a lack of treatment information are associated with higher levels of treatment burden, ${ }^{14}$ optimising relationships is important.

Care that is individualised, holistic, respectful and empowering, that is, patient-centred care, ${ }^{15}$ can facilitate the development of professional and patient relationships. ${ }^{16}$ Indeed, this approach to healthcare has also been shown to influence a consumer's choice of pharmacy ${ }^{17}$ and their perceptions of service quality. ${ }^{18}$ Yet while patient-centred care involves providing services that meet patient or consumer needs, or are delivered in an appropriate way, or both, there has been minimal research into the importance of pharmacy services that are patient centred, from the perspective of consumers. For example, researchers have explored consumer views of patient-centred professionalism in the context of community pharmacy, ${ }^{19-21}$ but not with respect to actual services. The majority of pharmacy studies have evaluated consumer perceptions of specific services or the role of pharmacists in community pharmacy, ${ }^{22-25}$ consumer preferences or priorities with respect to a specific service or role, ${ }^{26}{ }^{27}$ or how services could be improved for specific populations. ${ }^{2}$ Despite recognising the importance of identifying what consumers want or expect from community pharmacy, ${ }^{26}{ }^{28}$ their views have only been researched from limited perspectives.

There is also limited information as to what pharmacists think consumers want with respect to patient-centred pharmacy services. Most studies have generally explored pharmacists' perceptions $^{29}{ }^{30}$ or preferences ${ }^{31} 32$ for extended or future roles, or patient-centred services. Therefore, the results may not be aligned with what consumers actually want. Recently, Assa-Eley and Kimberlin ${ }^{33}$ explored the congruence of pharmacist and patient perceptions with respect to services that would benefit patients. As hypothesised, pharmacists considered services to be more beneficial than patients, for example, explaining how to use their medicines and asking questions to identify medication problems. ${ }^{33}$ However, this American study only included pharmaceutical care services that solely focused on the quality use of medicines. ${ }^{33}$ Consequently, further research is needed to explore pharmacist and consumer views in relation to other patient-centred pharmacy services.
In the Australian context, some professional pharmacy services are funded by agreements made every 5 years between the Government and a key professional organisation, known as the Community Pharmacy Agreement. It is expected that this research will inform healthcare professionals and policymakers as to what pharmacy services should be prioritised from a consumer perspective. More importantly, it goes beyond how people use the pharmacy, which most research has focused on, to identifying what services are important to them. This research is particularly important for people with chronic conditions and their carers, who can experience high levels of treatment burden ${ }^{14}$ and frequently access community pharmacies. Furthermore, with the Australian Government planning to introduce a copayment for Australian residents to see their general practitioner (GP) ${ }^{34}$ it could be anticipated that more of these consumers will seek help from their community pharmacy.

Overall, this study aims to recognise the purpose/s for which Australian residents with chronic conditions and their carers currently use community pharmacy, and compare this to what pharmacy services they consider important, from the perspective of both consumers and pharmacists.

\section{METHOD}

This study was part of a larger project exploring consumers' perspectives on the burden of chronic conditions and the role of community pharmacy to help manage these conditions. This project incorporated semistructured interviews, groups using the nominal group technique and a self-reported survey. Data were selected from the survey to address the study aims above. The remaining data were collected for other purposes, for example, an evaluation of the treatment burden and a Discrete Choice Experiment, and are ${ }^{35}$ (or will be) reported elsewhere.

\section{Participants}

A diverse, purposive sample of people with chronic conditions, unpaid carers and health professionals, for example, pharmacists, doctors and allied health professionals, were recruited from four Australian regions: Logan-Beaudesert and Mt Isa/North West region, Queensland, Northern Rivers, New South Wales, and the Greater Perth area, Western Australia. For this study, only the data from consumers, carers and pharmacists were selected. Other health professional data were excluded as they are not directly involved in the core delivery of pharmacy services, and were therefore not related to the aims of this study. Consumers and carers were required to meet at least one of the eligibility criteria (box 1). The purpose of the sample was to represent diversity in location, age, socioeconomic status, culture and chronic condition/s. This ensured the recruitment of people with varying health complexities and experiences with community pharmacy, including 


\section{Box 1 Eligibility criteria for study participants*}

Have one or more long-term health condition(s) for at least 6 months.

Recently diagnosed with a long-term health condition (in the previous 6 months).

Recently started to use pharmacy services (eg, blood pressure testing).

Take five or more regular medications.

Take more than 12 doses of medication each day.

Experienced difficulties/significant changes to medication routine in the past 3 months.

High user of medical services (eg, visit a general practitioner at least 12 times annually).

Qualified for cheaper prescription medication this year or last year (medication payment subsidy paid by the Australian Government). Aboriginal or Torres Strait Islander who qualifies for the 'Closing the Gap' copayment (medication payment subsidy paid by the Australian Government).

Care for someone with a chronic condition.

${ }^{*}$ Consumers had to either have a chronic condition or be an unpaid carer. The other criteria were used to ensure participant diversity.

those eligible for more in-depth services such as medication management services, for example, MedsCheck (a form of medication review), which would provide a different pharmacy experience. Pharmacists were eligible to participate in the study if they had recently or currently worked in a community pharmacy within one of the four project areas, and therefore were expected to have knowledge of current pharmacy practice. Participant recruitment involved the targeted provision of study information and enrolment in a variety of locations, for example, medical practices, healthcare clinics, community pharmacies, shopping centres and formats, for example, newspaper articles and advertisements. Further information was provided to non-government consumer health organisations, for example, Diabetes Australia, and professional bodies, for example, The Pharmaceutical Society of Australia.

\section{Survey development}

The survey was informed by previous project findings, including semistructured interviews ${ }^{17} 36$ and nominal groups. ${ }^{37}$ The survey was comprehensive as it addressed several aims of the overall project. To address the aims of this study, the survey asked consumers to indicate which pharmacy services they had ever used, that is, by ticking all the services that applied, as well as to rate the importance of each service on a visual analogue scale of $0-100$, that is, $100=$ the pharmacy service has a very high importance for me and $0=$ this pharmacy service is not important to me. The visual analogue scale was selected after discussion between research project members, as there were no validated scales for this measurement, and we wished to capture subtle variations in opinions which are not possible with a more truncated scale, that is, $0-10$. As previous stages of the project have identified that pharmacies are commonly utilised for medication access, ${ }^{36} 38$ survey questions focused beyond this service. Identical questions were given to community pharmacists, except that they were asked to consider the services that their consumers would like from pharmacy or pharmacists to help them with their situation, not what they would personally want as a pharmacist.

Feedback on the survey was obtained from iterative rounds of pilot testing with consumers and health professionals, the project Reference Group and Advisory Panel (both of which consisted of a range of key healthcare stakeholders), and a plain English reviewer. Minor changes were made to improve the readability of the survey for people who may have limited literacy levels.

\section{Study procedure}

The survey was conducted between October 2013 and January 2014. Study information and surveys were first posted or emailed to potential participants, who were subsequently contacted to confirm a date and time for a telephone or face-to-face interview. The majority of participants were guided through a telephone interview with a consumer-assisted telephone interview provider, who recorded the responses. However, some surveys were conducted face to face by the researchers, particularly for groups who preferred this approach or were considered difficult to reach via telephone. Both verbal and written consent were obtained prior to data collection.

\section{Data analysis}

Survey results were analysed descriptively, with the median and IQR identified for each pharmacy service. SPSS V.22 was used for statistical analysis.

\section{RESULTS}

Overall, 849 consumers and carers expressed interest in the survey with a total of 602 participants $(70.9 \%$ response). The majority of participants were female $(68.5 \%)$, had an annual household income of below \$A50 $000(60.5 \%)$, experienced two or more chronic conditions $(83.2 \%)$, and had a mean age of 57.0 years (range 17-89 years). From the 601 participants who identified their ethnic or cultural background, $61.3 \%$ $(n=368)$ were Australian, 9.0\% ( $n=54)$ were Aboriginal and Torres Strait Islander peoples, and 29.7\% ( $\mathrm{n}=179)$ were culturally and linguistically diverse. Most participants were from the Logan-Beaudesert region $(n=236$; $39.2 \%)$, followed by Northern Rivers ( $\mathrm{n}=191 ; 31.7 \%)$, then Greater Perth $(n=133 ; 22.1 \%)$ and the Mt Isa/ North West region $(n=42 ; 7.0 \%)$. The most common conditions reported included high blood pressure, arthritis, chronic pain, depression, anxiety and asthma.

From the 412 healthcare professionals expressing interest, 297 participated (72.1\% response), including 91 pharmacists. The majority of pharmacists were female (68.1\%), Australian $(57.1 \%)$, had practised for five or more years $(63.7 \%)$, and had a mean age of 37.5 years 
Table 1 Pharmacy services used by consumers and carers (survey)

\begin{tabular}{|c|c|c|c|c|c|c|c|c|}
\hline & \multicolumn{2}{|c|}{$\begin{array}{l}\text { Consumers } \\
(n=442)\end{array}$} & \multicolumn{2}{|c|}{ Carers (n=21) } & \multicolumn{2}{|c|}{ Both $(n=139)$} & \multicolumn{2}{|c|}{ Total $^{*}(n=602)$} \\
\hline & n & Per cent & $\mathbf{n}$ & Per cent & n & Per cent & n & Per cent \\
\hline \multicolumn{9}{|l|}{ Type of pharmacy services accessed $†$} \\
\hline Discussing medications at pharmacy & 280 & 63.8 & 15 & 75.0 & 102 & 73.9 & 397 & 66.5 \\
\hline Deciding to see a doctor & 135 & 30.8 & 6 & 30.0 & 54 & 39.1 & 195 & 32.7 \\
\hline Health screening/monitoring & 102 & 23.2 & 5 & 25.0 & 45 & 32.6 & 152 & 25.5 \\
\hline Home deliveries & 81 & 18.5 & 5 & 25.0 & 37 & 26.8 & 123 & 20.6 \\
\hline Dose administration aids & 60 & 13.7 & 6 & 30.0 & 34 & 24.6 & 100 & 16.8 \\
\hline Discussing medications at home§ & 58 & 13.2 & 3 & 15.0 & 23 & 16.7 & 84 & 14.0 \\
\hline Weight management & 36 & 8.2 & 1 & 5.0 & 13 & 9.4 & 50 & 8.4 \\
\hline Needle and syringe exchange & 33 & 7.5 & 0 & 0 & 11 & 8.0 & 44 & 7.4 \\
\hline Quit programme & 22 & 5.0 & 1 & 5.0 & 13 & 9.4 & 36 & 6.0 \\
\hline Glucometer testing & 22 & 5.0 & 0 & 0 & 9 & 6.5 & 31 & 5.2 \\
\hline Vaccinations & 20 & 4.6 & 0 & 0 & 8 & 5.8 & 28 & 4.7 \\
\hline None of these services & 78 & 17.8 & 3 & 15.0 & 15 & 10.9 & 96 & 16.0 \\
\hline Other serviceף & 37 & 8.4 & 0 & 0 & 17 & 12.3 & 54 & 9.0 \\
\hline \multicolumn{9}{|c|}{$\begin{array}{l}\text { *Type of services accessed at the pharmacy had missing/incomplete data. Percentages are based on the actual number of individual } \\
\text { responses. } \\
\text { †Total for the type of pharmacy services accessed exceeds } 100 \% \text { as respondents were asked to indicate all that applied. } \\
\text { †Discussing medications at the pharmacy could be an ad hoc discussion or counselling session, or involve a more structured professional } \\
\text { service such as a MedsCheck. } \\
\text { §Known as a home medication review in Australia. } \\
\text { IIncluded returning unused medications, naturopathy, bone density testing, etc. }\end{array}$} \\
\hline
\end{tabular}

(range, 22-66 years). More participants worked in Perth $(36.2 \%)$, followed by Logan-Beaudesert (29.7\%), Northern Rivers $(26.4 \%)$ and the Mt Isa/North West region $(7.7 \%)$. Small proportions of pharmacists cared for someone with $(16.5 \%)$, or had $(9.9 \%)$, one or more chronic condition/s, or both $(4.4 \%)$.

\section{Community pharmacy use}

The pharmacy service accessed most frequently by consumers and carers was the opportunity to discuss their medication ( $\mathrm{n}=397 ; 66.5 \%)$, followed by advice as to whether a GP's appointment was needed $(n=195$; $32.7 \%)$ and then health screening and monitoring $(\mathrm{n}=152 ; 25.5 \%)$. Home deliveries and dose administration aids were less frequently utilised services; however, carers were higher users of dose administration aids than other consumer participants (table 1).

The importance of specific pharmacy services: consumer, carer and pharmacist perspectives

The most important services for consumers and carers in the survey were those with a median score of 90 or above, and the least important services were those with a median score below 50 (table 2). Overall, community pharmacists had a good understanding of the services that were important to people with chronic conditions and their carers. For example, the two highest (most important) and two lowest (least important) rated characteristics of pharmacy services were identical for both groups (table 2). The most important service characteristics for consumers and carers (as a combined total group), as verified by pharmacists, were related to how services were provided, that is, individualised and respectful care. High ratings were also associated with actual services or service characteristics, such as those relating to medication management ('provide personalised advice and information on prescribed medicines') and new services for Australia ('prescribe a short course of medication under a healthcare plan that has been agreed with the GP, without needing to see a GP'). The least important services or service characteristics were the provision of community health and wellness programmes and adult vaccinations.

With respect to differences in opinion, pharmacists overestimated the importance of advice on minor ailments and the pharmacist's availability for consultations, that is, positioned outside of the dispensary, to consumers and carers. Pharmacists also underestimated the importance of improved access to medication, such as prescription reminders and access to a consumer's dispensing history from all pharmacies.

There were also some differences between what people with chronic conditions and their carers believed were important pharmacy services. Services that assisted carers with role/s, such as being a partner in the healthcare of the care-receiver, home deliveries, repeat prescription reminders, monitoring and screening services, and for the pharmacist to be available for consultations in a variety of ways, including via email and telephone, were viewed as important. Carers also placed greater importance on a private consultation area to discuss medication than participants with chronic conditions. Alternatively, respecting personal needs and values was more important for consumers. 
Table 2 The importance of specific community pharmacy services in helping to manage the chronic conditions of consumers and/or unpaid carers

\begin{tabular}{|c|c|c|c|c|c|c|c|c|c|c|}
\hline \multirow[b]{2}{*}{ Future community pharmacy service } & \multicolumn{2}{|c|}{$\begin{array}{l}\text { Consumers } \\
(n=442)\end{array}$} & \multicolumn{2}{|c|}{ Carers $(n=21)$} & \multicolumn{2}{|c|}{$\begin{array}{l}\text { Consumers/ } \\
\text { carers (both; } \\
\mathrm{n=139} \text { ) }\end{array}$} & \multicolumn{2}{|c|}{ Total $(n=602)$} & \multicolumn{2}{|c|}{$\begin{array}{l}\text { Pharmacists } \\
(n=91)\end{array}$} \\
\hline & Median & $\overline{\text { IQR }^{\star}}$ & Median & IQR $^{\star}$ & Median & IQR $^{\star}$ & Median & IQR $^{\star}$ & Median & IQR $^{*}$ \\
\hline Treat me as an individual, not as a number & 100.0 & 20.0 & 100.0 & 20.0 & 100.0 & 20.0 & 100.0 & 20.0 & 100.0 & 10.0 \\
\hline Be respectful of needs and personal values & 100.0 & 25.0 & 80.0 & 25.0 & 95.0 & 20.0 & 98.5 & 25.0 & 100.0 & 7.5 \\
\hline Provide personalised advice and information on prescribed medicines & 90.0 & 30.0 & 99.0 & 25.0 & 90.0 & 25.0 & 90.0 & 25.0 & 90.0 & 20.0 \\
\hline Have access to my prescription (dispensing) records from any pharmacy & 90.0 & 45.0 & 100.0 & 20.0 & 90.0 & 40.0 & 90.0 & 40.0 & 80.0 & 30.0 \\
\hline Be a partner in healthcare (eg, work with me and my family) & 80.0 & 50.0 & 100.0 & 20.0 & 80.0 & 40.0 & 80.0 & 50.0 & 80.0 & 30.0 \\
\hline $\begin{array}{l}\text { Prescribe a short course of medication under a healthcare plan that has been } \\
\text { agreed with the GP, without needing to see the GP }\end{array}$ & 80.0 & 50.0 & 90.0 & 45.0 & 75.0 & 50.0 & 80.0 & 50.0 & 80.0 & 20.0 \\
\hline Recognise and value all parts of my life & 80.0 & 50.0 & 75.0 & 45.0 & 80.0 & 50.0 & 80.0 & 50.0 & 90.0 & 20.0 \\
\hline Have access to my medical records, with links to my GP, specialist/hospital & 80.0 & 50.0 & 90.0 & 40.0 & 80.0 & 50.0 & 80.0 & 50.0 & 70.0 & 30.0 \\
\hline Offer advice on the management of minor ailments & 75.0 & 40.0 & 75.0 & 40.0 & 75.0 & 45.0 & 75.0 & 40.0 & 90.0 & 20.0 \\
\hline Be available in the pharmacy but away from the dispensary for consultation & 70.0 & 40.0 & 77.5 & 42.5 & 75.0 & 40.0 & 75.0 & 40.0 & 90.0 & 20.0 \\
\hline Be able to speak with and put me in touch with other health professionals/services & 75.0 & 40.0 & 80.0 & 50.0 & 75.0 & 50.0 & 75.0 & 40.0 & 80.0 & 20.0 \\
\hline Prescribe an extra 6 months repeat medicines after the GP prescription runs out & 75.0 & 60.0 & 85.0 & 60.0 & 75.0 & 70.0 & 75.0 & 60.0 & 70.0 & 30.0 \\
\hline Send reminders when my repeat prescription is due & 75.0 & 54.0 & 85.0 & 50.0 & 75.0 & 50.0 & 75.0 & 50.0 & 50.0 & 20.0 \\
\hline Have a private consultation area for discussions about medicines and health & 68.0 & 45.0 & 82.5 & 75.0 & 75.0 & 40.0 & 70.0 & 40.0 & 90.0 & 25.0 \\
\hline Review my medicines-either in the pharmacy or at home & 70.0 & 60.0 & 80.0 & 75.0 & 75.0 & 40.0 & 70.0 & 50.0 & 80.0 & 20.0 \\
\hline Be available on the phone, internet or email for consultations & 60.0 & 60.0 & 72.5 & 45.0 & 72.5 & 30.0 & 70.0 & 50.0 & 80.0 & 20.0 \\
\hline Offer screening and monitoring services & 60.0 & 65.0 & 75.0 & 70.0 & 70.0 & 60.0 & 70.0 & 65.0 & 75.0 & 20.0 \\
\hline Offer home delivery for medicines & 55.0 & 65.0 & 67.5 & 80.0 & 70.0 & 70.0 & 60.0 & 65.0 & 75.0 & 30.0 \\
\hline Be located in a large community clinic/medical centre as part of a one-stop shop & 60.0 & 65.0 & 70.0 & 75.0 & 70.0 & 65.0 & 60.0 & 65.0 & 70.0 & 30.0 \\
\hline Have other health providers working at the pharmacy & 60.0 & 50.0 & 70.0 & 30.0 & 65.0 & 65.0 & 60.0 & 50.0 & 60.0 & 25.0 \\
\hline Provide basic adult vaccinations or treatments & 50.0 & 70.0 & 60.0 & 70.0 & 50.0 & 65.0 & 50.0 & 60.0 & 50.0 & 30.0 \\
\hline Offer community health and wellness programmes & 50.0 & 60.0 & 40.0 & 60.0 & 50.0 & 70.0 & 50.0 & 65.0 & 40.0 & 25.0 \\
\hline
\end{tabular}




\section{DISCUSSION}

Overall, participants primarily utilise community pharmacies for medication advice, which corroborates findings from the project's semistructured interviews ${ }^{36}$ and a recent Australian study. ${ }^{5}$ Indeed, all parties, consumers, carers and pharmacists, recognised the importance of pharmacists to provide individualised medication advice. This outcome aligns with our study population who are likely to be regular medication users, carers who assist with medication management, or both. This is therefore a service that pharmacies need to continue to deliver to this population, with an emphasis also on how it is delivered, that is, in a personalised way. Ultimately, when asked to rate the importance of specific pharmacy services, how services were delivered rated higher than what was delivered. Although there were differences in importance ratings for some services between pharmacists and consumers and carers, in this respect, pharmacists were of the same opinion, demonstrating a good understanding of what was important to these consumers, that is, patient-centred care.

\section{Strengths and limitations}

By exploring what services are important to people with chronic conditions and their carers, and how this differs from their current use of pharmacy and the views of pharmacists, this study provides valuable insights regarding service development and delivery for these consumers. There has been limited research in this area for such a diverse group of people with chronic conditions, or carers, and a further strength of this study was its consumer-driven approach. Furthermore, this study was informed by previous findings from the larger project, ${ }^{17}$ 36-38 which also strengthens the above results. However, there are some limitations to this work. The results may not be generalisable to countries with different healthcare systems from Australia. The researchers could not ascertain if the services participants did not access were actually available in the pharmacy they used. There was also the risk of investigator bias caused by utilising a mixture of face-to-face and telephone data collection methods. However, this is also recognised as a strength in terms of data triangulation, and ensured that groups that might be considered difficult to reach, including Aboriginal and Torres Strait Islander peoples and culturally and linguistically diverse participants, had the opportunity to participate. Finally, while the survey included a large and diverse sample of consumers, the number of participants who were carers and not consumers was smaller, potentially limiting the comparison between consumer and carer perspectives expressed in the survey.

Considering that there is a greater emphasis on a patient-centred approach to healthcare,${ }^{39}$ it is reassuring to see that Australian pharmacists understand the importance of how services are delivered to people with chronic conditions and their carers. However, while studies have reviewed patient-pharmacist interactions for patient-centred communication, ${ }^{40}$ and explored what patient-centred professionalism means within the pharmacy context, ${ }^{19-21}$ research exploring the application of patient-centred care within a community pharmacy setting is limited. It is clearly evident that pharmacists and community pharmacy are missing from the literature on patient-centred interventions, ${ }^{4}$ and that further research is needed in this area. Moreover, professional pharmacy organisations should provide further assistance to pharmacies to develop patient-centred services. Assistance could include a support unit including online resources and training for pharmacy staff, and assistance for pharmacists to tailor services to individual clients. Indeed, integration of patient-centred training of pharmacy students into clinical training must be advocated. ${ }^{42}$

The service most commonly accessed by consumers and carers was medication advice. However, this was not the case for one-third of participants. This could be due to a number of reasons, for example, these participants may not need advice as they have been managing their condition/s for a long period of time. Alternatively, consumers may not seek information from community pharmacists because of a lack of awareness of the pharmacist's role or expertise, ${ }^{36}$ or the current pharmacy environment. Similar factors are also believed to influence the provision of patient-centred professionalism by the pharmacist. ${ }^{21}$ It is often suggested that community pharmacists consider their physical working environment, ${ }^{21}$ such as improving the lack of privacy, ${ }^{43} 44$ which can impact on the public trust of pharmacists. ${ }^{4}$ However, in this study, a private consultation room was of lower importance for people with chronic conditions when rating pharmacy service characteristics. Furthermore, pharmacists overestimated the value of a private consultation room. It may be that how pharmacy staff communicate with consumers is more relevant than the actual space when it comes to respecting privacy. The importance of tailoring information by taking into account a person's context and experiences, as well as developing a relationship to facilitate this information sharing, is in accord with previous research. ${ }^{45}$ Our study corroborates that information on prescribed medication is what people with chronic conditions and their carers rate as important from community pharmacies, even if they do not currently utilise this service.

There are clear opportunities for community pharmacy to become more involved in supporting consumers to manage their chronic condition/s, and to further assist carers. These include new roles for pharmacists, such as prescribing a short course of medication under a GP's agreed healthcare plan, as well as implementing tools to facilitate continuity and coordinated care, such as a person's medication dispensing history linked to all community pharmacies. The importance of continued medication supply was also confirmed by two other studies undertaken within the larger project, ${ }^{35}{ }^{37}$ and support for this role by Australian consumers has been underscored by Hoti et $a l^{46}$ This is even more relevant given that their study recruited similar consumers to our 
study, that is, people who were regularly using prescription medication. ${ }^{4}$

Medication management and supply services, such as repeat prescription reminders, home deliveries, and the opportunity to obtain a pharmacist's advice in a way that best suited them, for example, online or face to face, was more important for carers than for people with chronic conditions. Despite the smaller number of carers in our sample (relative to consumers), these results emphasise the importance of these specific services to reduce carer burden. Yet the importance of prescription reminders was underestimated by pharmacists in the survey. Given that this service is relatively easy to implement, for example, verbal or short message service (SMS) text reminders for prescription renewal, this should become, if it is not already, common practice in Australian pharmacies. Australian pharmacists should also consider the study findings before discontinuing, reducing the availability, or increasing the costs of home delivery services. ${ }^{47}$ At the very least, this service should be offered to the carers that utilise their pharmacy.

People with chronic conditions and their carers placed lower importance on pharmacists or pharmacies offering health and wellness programmes, or providing basic adult vaccinations. Pharmacists corroborated this finding. This research did not explore the reasons behind why certain services were more important than others, and so we can only hypothesise. It is plausible that participants were focusing on the daily management of their condition rather than preventative measures when completing the survey. People who have lived with a chronic condition for a long time can become well informed about their condition/s, particularly with how it affects them, ${ }^{48}$ and many would be eligible for influenza or pneumococcal vaccination, at no extra cost, during their GP consultation.

\section{CONCLUSION}

Overall, pharmacists had a reasonable understanding of what consumers with chronic conditions and their carers would rate as important in terms of pharmacy services. Greater value was placed on how pharmacy services are delivered, that is, in a patient-centred manner, particularly when providing medication information. Ultimately, pharmacists understood the importance of patient-centred care for people with chronic conditions and their carers, perhaps indicating a greater acceptance of integrating patient-centred care into their everyday practice.

\section{Author affiliations}

${ }^{1}$ Griffith Health Institute, Griffith University, Meadowbrook, Queensland, Australia

${ }^{2}$ School of Pharmacy, Faculty of Medical and Health Sciences, University of Auckland, Auckland, New Zealand

${ }^{3}$ School of Allied Health, Australian Catholic University, Banyo, Queensland, Australia

${ }^{4}$ Griffith Health Institute, School of Pharmacy, Griffith University, Southport, Queensland, Australia

${ }^{5}$ School of Pharmacy, University of Queensland, Woolloongabba, Queensland, Australia
Acknowledgements The authors wish to thank all participants for their time, the project team who assisted with participant recruitment, Professor Elizabeth Kendall for her advice, and Claire Campbell and Ciara McLennan for their help with conducting interviews.

Contributors FK, MAK, JAW and AJW participated in the design of the main study. All authors were involved in the survey design, and SSM and AS assisted with data collection. SSM, AS and FK analysed the data pertaining to this study. SSM drafted the manuscript and all authors provided editorial comments. All authors also read and approved the final manuscript.

Funding This work was supported by the Australian Government Department of Health as part of the Fifth Community Pharmacy Agreement Research and Development Programme managed by The Pharmacy Guild of Australia. The financial assistance provided must not be taken as endorsement of the contents of this study

\section{Competing interests None.}

Ethics approval This study was approved by the Griffith University Human Research Ethics Committee (PHM/12/11/HREC).

Provenance and peer review Not commissioned; externally peer reviewed.

Data sharing statement The larger study in which this sits is being published as a report, which was submitted to the Department of Health and The Pharmacy Guild of Australia in August 2014. Further information on this larger study is available here: http://5cpa.com.au/programs/research-anddevelopment.

Open Access This is an Open Access article distributed in accordance with the Creative Commons Attribution Non Commercial (CC BY-NC 4.0) license, which permits others to distribute, remix, adapt, build upon this work noncommercially, and license their derivative works on different terms, provided the original work is properly cited and the use is non-commercial. See: http:// creativecommons.org/licenses/by-nc/4.0/

\section{REFERENCES}

1. Guerreiro M, Cantrill J, Martins P. Acceptability of community pharmaceutical care in Portugal: a qualitative study. J Health Serv Res Policy 2010;15:215-22.

2. Wood K, Gibson F, Radley A, et al. Pharmaceutical care of older people: what do older people want from community pharmacy? Int J Pharm Pract. Published Online First: 6 June 2014. doi: 10.1111/ijpp. 12127

3. Schommer JC, Gaither CA. A segmentation analysis for pharmacists' and patients' views of pharmacists' roles. Res Social Adm Pharm 2014;10:508-28.

4. Gidman W, Ward P, McGregor L. Understanding public trust in services provided by community pharmacists relative to those provided by general practitioners: a qualitative study. BMJ Open 2012;2:pii: e000939.

5. PricewaterhouseCoopers, The Pharmacy Guild of Australia, The Australian Government Department of Health. Consumer Needs Project [unpublished report]. 2014. http://5cpa.com.au/programs/ research-and-development/current-projects/consumer-needs/

6. Mott K, Eltridge F, Gilbert A, et al. Consumer experiences, needs and expectations of community pharmacy. 2005. http://www.guild. org.au/services-programs/research-and-development/archive-thirdagreement/2005-501

7. Dispensing Health. Who do you think we are? Community Pharmacy: Dispensers of Health. 2014. http://www.dispensinghealth. org/wp-content/uploads/2014/01/DH-Launch-FINA1.pdf

8. Canadian Pharmacists Association. Pharmacist awareness month 2014. http://www.pharmacists.ca/index.cfm/news-events/events/ pharmacist-awareness-month-pam/ (accessed 15 Oct 2014).

9. The Pharmacy Guild of Australia. Campaign update. Forefront 2014;4. http://guild.org.au/news-events/forefront/volume-4-number39/campaign-update

10. Hersberger KE, Botomino A, Mancini M, et al. Sequential screening for diabetes-evaluation of a campaign in Swiss community pharmacies. Pharm World Sci 2006;28:171-9.

11. Lisper B, Nilsson JL. The asthma year in Swedish pharmacies: a nationwide information and pharmaceutical care program for patients with asthma. Ann Pharmacother 1996;30:455-60.

12. Roughead EE, Kalisch Ellett LM, Ramsay EN, et al. Bridging evidence-practice gaps: improving use of medicines in elderly Australian veterans. BMC Health Serv Res 2013;13:514. 
13. Wutzke SE, Artist MA, Kehoe LA, et al. Evaluation of a national programme to reduce inappropriate use of antibiotics for upper respiratory tract infections: effects on consumer awareness, beliefs, attitudes and behaviour in Australia. Health Promot Int 2007;22:53-64

14. Sav A, King MA, Whitty JA, et al. Burden of treatment for chronic illness: a concept analysis and review of the literature. Health Expect. Published Online First: 31 January 2013. doi: 10.1111/hex. 12046

15. Morgan S, Yoder LH. A concept analysis of person-centered care. $J$ Holist Nurs 2012;30:6-15.

16. Mey A, Knox K, Kelly F, et al. Trust and safe spaces: mental health consumers' and carers' relationships with community pharmacy staff. Patient 2013;6:281-9.

17. McMillan SS, Sav A, Kelly F, et al. How to attract them and keep them: the pharmacy attributes that matter to Australian residents with chronic conditions. Int J Pharm Pract 2013;22:238-45.

18. Knox K, Kelly F, Mey A, et al. Australian mental health consumers' and carers' experiences of community pharmacy service. Health Expect. Published Online First: 11 March 2014. doi: 10.1111/hex. 12179

19. Rapport F, Doel MA, Hutchings HA, et al. Eleven themes of patient-centred professionalism in community pharmacy: innovative approaches to consulting. Int J Pharm Pract 2010;18:260-8.

20. Hutchings HA, Rapport FL, Wright $\mathrm{S}$, et al. Obtaining consensus regarding patient-centred professionalism in community pharmacy: nominal group work activity with professionals, stakeholders and members of the public. Int J Pharm Pract 2010;18:149-58.

21. Elvey R, Lewis $P$, Schafheutle E, et al. Patient-centred professionalism among newly registered pharmacists. 2011. http:// www.pharmacyresearchuk.org/waterway/wp-content/uploads/2012/ 11/Patient_centred_professionalism_in_newly_registered_ pharmacists.pdf

22. Latif A, Pollock K, Boardman HF. The contribution of the Medicines Use Review (MUR) consultation to counseling practice in community pharmacies. Patient Educ Couns 2011;83:336-44.

23. McCann LM, Haughey SL, Parsons $\mathrm{C}$, et al. A patient perspective of pharmacist prescribing: 'crossing the specialisms-crossing the illnesses'. Health Expect. Published Online First: 15 October 2012. doi: 10.1111/hex.12008

24. Weidmann AE, Cunningham S, Gray G, et al. Views of the Scottish general public on community pharmacy weight management services: international implications. Int J Clin Pharm 2012;34:389-97.

25. Tarn DM, Paterniti DA, Wenger NS, et al. Older patient, physician and pharmacist perspectives about community pharmacists' roles. Int J Pharm Pract 2012;20:285-93.

26. Tinelli M, Ryan M, Bond C. Patients' preferences for an increased pharmacist role in the management of drug therapy. Int $J$ Pharm Pract 2009;17:275-82.

27. Naik-Panvelkar P, Armour C, Rose JM, et al. Patient preferences for community pharmacy asthma services: a discrete choice experiment. Pharmacoeconomics 2012;30:961-76.

28. Renberg T, Wichman Tornqvist K, Kalvemark Sporrong S, et al. Pharmacy users' expectations of pharmacy encounters: a Q-methodological study. Health Expect 2011;14:361-73.

29. Mak VSL, Clark A, Poulsen JH, et al. Pharmacists' awareness of Australia's health care reforms and their beliefs and attitudes about their current and future roles. Int J Pharm Pract 2012;20:33-40.
30. Dobson RT, Taylor JG, Henry CJ, et al. Taking the lead: community pharmacists' perception of their role potential within the primary care team. Res Social Adm Pharm 2009;5:327-36.

31. Grindrod KA, Marra CA, Colley L, et al. Pharmacists' preferences for providing patient-centered services: a discrete choice experiment to guide health policy. Ann Pharmacother 2010;44:1554-64.

32. Scott A, Bond C, Inch J, et al. Preferences of community pharmacists for extended roles in primary care: a survey and discrete choice experiment. Pharmacoeconomics 2007;25:783-92.

33. Assa-Eley M, Kimberlin CL. Using interpersonal perception to characterize pharmacists' and patients' perceptions of the benefits of pharmaceutical care. J Health Commun 2005;17:41-56.

34. Wilson A. Budget cuts risk halting Australia's progress in preventing chronic disease. Med J Aust 2014;200:558-9.

35. Whitty JA, Kendall E, Sav A, et al. Preferences for the delivery of community pharmacy services to help manage chronic conditions. Res Social Adm Pharm. Published Online First: 15 July 2014. doi: 10.1016/j.sapharm.2014.06.007

36. McMillan SS, Kelly F, Sav A, et al. Consumer and carer views of Australian community pharmacy practice: awareness, experiences and expectations. J Pharm Health Serv Res 2014;5:29-36.

37. McMillan SS, Sav A, Kelly F, et al. Is the pharmacy profession innovative enough? meeting the needs of Australian residents with chronic conditions and their carers using the nominal group technique. BMC Health Serv Res 2014;14:476.

38. McMillan SS, Wheeler AJ, Sav A, et al. Community pharmacy in Australia: the health hub destination of the future. Res Social Adm Pharm 2013;9:863-75.

39. Australian Commission on Safety and Quality in Health Care. Patient-centred care: improving quality and safety through partnerships with patients and consumers. 2011. http://www.safetyandquality.gov. au/wp-content/uploads/2012/03/PCC_Paper_August.pdf

40. Murad MS, Chatterley T, Guirguis LM. A meta-narrative review of recorded patient-pharmacist interactions: exploring biomedical or patient-centered communication? Res Social Adm Pharm 2014;10:1-20.

41. McMillan SS, Kendall E, Sav A, et al. Patient centred approaches to health care: a systematic review of randomized controlled trials. Med Care Res Rev 2013;70:567-96.

42. Sanchez AM. Teaching patient-centered care to pharmacy students. Int J Clin Pharm 2011;33:55-7.

43. Krska J, Morecroft CW. Views of the general public on the role of pharmacy in public health. J Pharm Health Serv Res 2010;1:33-8.

44. Twigg MJ, Poland F, Bhattacharya D, et al. The current and future roles of community pharmacists: views and experiences of patients with type 2 diabetes. Res Social Adm Pharm 2012;9:777-89.

45. Hamrosi KK, Aslani P, Raynor DK. Beyond needs and expectations: identifying the barriers and facilitators to written medicine information provision and use in Australia. Health Expect 2014:17:220-31.

46. Hoti K, Hughes J, Sunderland B. Pharmacy clients' attitudes to expanded pharmacist prescribing and the role of agency theory on involved stakeholders. Int J Pharm Pract 2011;19:5-12.

47. The Pharmacy Guild of Australia. Pharmacy Services Expectations Report. 2014. http://www.guild.org.au/docs/default-source/publicdocuments/issues-and-resources/pharmacy-services-expectationssurvey-report-april-20141ed28133c06d6d6b9691ff000026bd16.pdf? sfvrsn=0

48. Tyreman S. An expert in what? The need to clarify meaning and expectations in "The Expert Patient". Med Health Care Philos 2005;8:153-7. 